\title{
RELATIONSHIP BETWEEN THE TRANSMISSIBILITY OF THE "ATHENS SCHISTS" AND THE PERCENTAGE OF THEIR COMPETENT ROCK COMPONENT
}

\author{
G. D. Kounis ${ }^{1}$ and K. G. Kounis ${ }^{2}$ \\ ${ }^{1}$ Hydrogeologist, Former Director of Hydrogeology,and Advisor at IGME, gdkounis@gmail.com \\ ${ }^{2}$ Consultant in Civil and Underground Works Engineering , kkouniscve@yahoo.com
}

\begin{abstract}
Aquitard formations consisted principally of "soft", ductile schists, crystalline or not, including, as a minor component, thin intercalations of "hard" rocks, like carbonates, quartzites, sandstones, quartz veinlets and the alike, though of low transmissibility, and thus very low yielding, are of great importance in some places where groundwater is demanded, especially in drought periods for irrigation of parks, and other uses.
\end{abstract}

To these formations belong the "Athens Schists" (from a long ago term, after R.Lepsius).

Formations like these, during the orogenic processes and their structural finishing, responded, under the compressive stresses, with a resultant normal extension strain contemporary or late, by folding affecting mostly the "plastic", ductile "soft", low rigidity components, by fracturing their competent, more rigid, "hard" components ; a fracturing hydraulically well performing, particularly that in carbonates which are better dissoluble into the circulating water.

Further, a very good measure of the yield of the unit saturation front under unit hydraulic head is the transmissibility of the formation, which in turn becomes a good decision making parameter in the exploitation of groundwater.

Therefore, the search for the correlation between the transmissibility $(T)$ of the "Athens Schist" and the percentage (Hr) of the brittle, "hard", hydraulically well performing component arised as a hydrogeologically sound idea.

A very good and positive relationship $T$ vs. Hr has been revealed, with an increase of transmissibility $(\Delta T)$ of "Athens Schists" per unit increase $(\Delta \mathrm{Hr})$ of the percentage found in the range of values.

$0.38 X 10^{-2}$ lit/sec.m.Hr $<\Delta T<0.72 X 10^{-2}$ lit/sec.m.Hr

Values of T are very low, as expected for a formation of the hydrolithology of the "Athens Schist", and mostly in between

$$
0.4 \times 10^{-2} \mathrm{lit} / \mathrm{sec} . \mathrm{m}<T<8.5 \times 10^{-2} \mathrm{lit} / \mathrm{sec} . \mathrm{m}
$$

The percentage $(\mathrm{Hr})$ of the hard member is commonly in the range of values

$$
2.8 \%<\mathrm{Hr}<17.5 \%
$$


Transmissibility is calculated under unsteady state conditions of pumping tests in boreholes, using the Jacob approach. Drawdown ( $s$ ) with time ( $t$ ) from start of pumping offers, with a very good accuracy, the appropriate linear segment on semi-logarithmic plot.

Values of $T$ from pumping test data representing longer pumping time and a more expanded cone of depression to wider rock mass showed recharge condition with delayed yield. However, dependence of $\mathrm{T}$ on $\mathrm{Hr}$ is again positive and very good.

The percentage (Hr) of the "hard" rock component of the "Athens Schist" was measured on drilling cuttings and in outcrops of the formation (excavations for buildings foundations etc) in the closer vicinity of boreholes, and results found were well comparable to each other.

Key words : Schists of Athens, transmissibility, hard rock, fracturing, lognormal distribution, correlation.

\section{Introduction}

Serving for many years, the first of the authors, the theory and field praxis in general geology and hydrogeology with a particular interest in applying new methods and views, the hydrogeological performance of the schists of Athens raised the idea to search for the reason of their groundwater to occur and flow, weakly but in acceptable yield for irrigation of parks and for other very local needs. Observations on different occasions on the schists of Athens and during the hydrogeological study he carried out in the context of Athens METRO project, as well as during a period of serious drought when he proposed and were drilled boreholes in the schists to exploit whatever ground water they could supply for irrigation of small plots were among the data to check-up the idea. (Kounis 1980). Other professional priorities kept aside the analysis and presentation of the subject, until this paper to appear.

In this paper we present the hydrogeological performance of the schists of Athens, and more specifically the response of the saturation zone to pumping in relation to the lithologic composition. We found a very good correlation between the transmissibility and the "hard", competent to fracturing, component of the formation. Sustainable yields are very low, as such are transmissibility values, and the case is that of an aquitard and of similar formations.

We present the generalized geological conditions i.e lithology, and structural geology of the wider environment of the schists to show and justify the state and the consequent hydrogeological performance. Going through the transmissibilities calculated from pumping tests and the percentage of "hard" rock, found out at specified sites of boreholes, we proceed to the formulation of the relationship between transmissibility and that percentage.

\section{General Geology}

Hereafter, the synoptic lithologic composition and the tectonic structure of the wider Athens basin, in which the "Athens Schists" ( after A. Lepsius nomenclature ) exist, are presented. Thus, the necessary information is given to show the relation between the state of the schists and their hydrogeological performance.

\subsection{Lithology}

In the area of the Athens basin exist Quaternary deposits in which are recognised eluvium,scree and alluvial fans. Eluvium, incoherent and mainly finegrained is present on the limestones of the Filopappou as well as on the Athens schists, and is less than $0.5 \mathrm{~m}$ thick. Scree on the Athens 


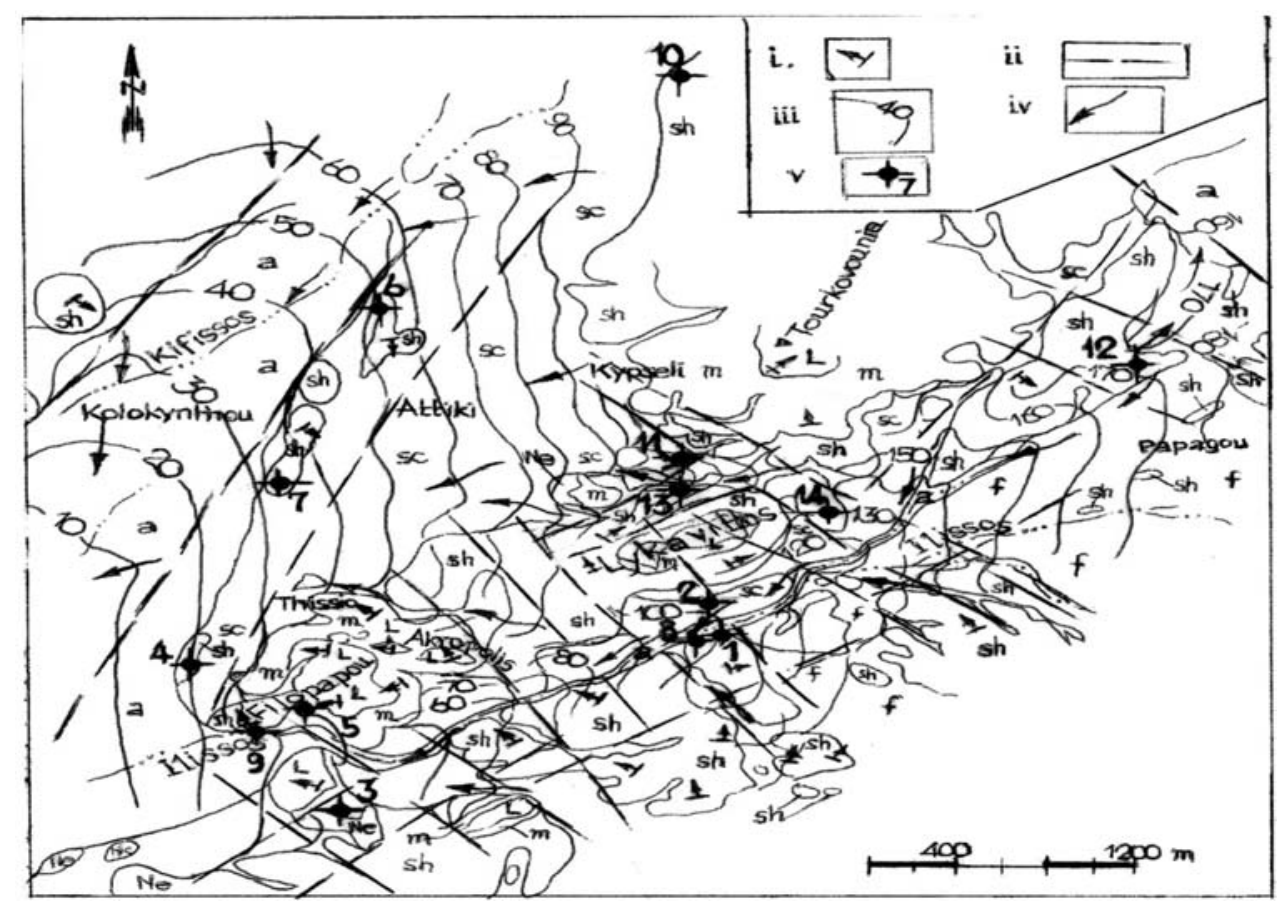

Fig. 1: Generalized hydrogeological map of the central Athens basin (sc: scree, young fans. a: alluvium along streams and plain morphology. f: alluvial fans. Ne: neogene. L: limestone, on the Athenian hills. m: marly limestones, marls, sandstones, conglomerates. sh: Schists of Athens. i: strike and dip of beds. ii: prequaternary fault. iii: GW level contour, masl. iv: predominant GW flow. v: borehole site, with ref. no).

hillslopes, is mainly medium to coarsegrained and less than $1 \mathrm{~m}$ thick (olocene). Alluvial fans from the mountainous environment are developed to valleys (Ilissos) and plain (Kifissos) deposits. Those from Hemyttos mountain are characteristically made of mixed clastics (marble, schists etc) principally coarse grained with an increased roundness and a slight sorting of their elements, a comparatively increased permeability, and locally compact. Erosion cuts them quite deeply in the older sectors to show terrace sections (Pleistocene). Calcareous are mostly the fans from Aegaleo Mt,with comparatively weak their rest of characteristics (Kounis, 1980).

Maximum thickness of quaternary in $98 \%$ of the sites measured was found less than $10 \mathrm{~m}$, particularly where it overlies the preneogene substratum, the latter being in the wider Athens area the Schists of Athens.

The Neogene (Pliocene) is represented by light coloured mostly limestones, commonly medium bedded, and by clastics of different coherence, of a wide granulometry, rather sorted, ranging from clays to basal conglomerate chiefly calcareous. It crops out at the boundary of the Kifissos graben and locally on hilly sites of the Athens area. (Strefi, Ghyzi etc ), while expected is under the quaternary of the downstream Kifissos zone. Observed thickness is less than $100 \mathrm{~m}$.

The preneogene substratum in descending stratigraphy is made of : The limestones of the Athens hills, light coloured, crystalline locally, brecciated or conglomerate towards their base (with fragments of rudistae and globotruncanae) (Katsikatsos, 2002).They overlie a characteristic clastic member from mixed, medium - finegrained sandstones, sandy marls and conglomerates, 
which seems to go transitionally to hardened marls and marly limestones (Katsikatsos et al., 1976).This clastic and marly member attains a thickness in between $20 \mathrm{~m}$ and $80 \mathrm{~m}$, while it resembles almost convincingly a transgression base of the sequence (Kounis, 1980).

Underlain are the Schists of Athens which are shaly, with usually thin sandstone layers, rarely clastic limestones, and sporadic small spilite and diabase bodies. They are equally chloritic ,sericitic schists with quartzites, graywackes and less frequently crystalline limestones, with the presence of all these metamorphics increasing with stratigraphic depth in the Schists. Maximum attained thickness is greater than $100 \mathrm{~m}$. In the metamorphic member crystalline limestone are locally a few meters thick, while quartzite layers rarery are $0.2 \mathrm{~m}$ thick,wedged out within 3m (Fig. 1) (Dounas et. al, 1976, Kounis, 1980, Gaitanakis, 1982).

\subsection{Tectonics}

The preneogene structural geology is expressed by a NWern principally, to W-SW compression, which has resulted in successive folds of NE axis mainly, most evident and intensive in the "plastic" schists mass of the structure, less pronounced in the calcareous, more elastic part. This geomechanic process is also well impressed in the underlain older structure, which is lifted particularly in the Pendelikon and Hymettus Mts,as well as in the rest of the metamorphosed Attica. The folding result on the Schists and the metamorphic geologic mass of the Athens basin as equally on the rest of metamorphic eastern Attica is very characteristic, dense and intensive, with very frequent the events of vertically erected or lain down folds. A very revealing evidence we recognise in the Pentelikon, with a dense sequence of synclines - anticlines of low wave length, even in the thick bedded "Lower Marble" (of A.Lepsius).Through a section of $3.5 \mathrm{~km}$ long only, 4 of the above binary forms can be mapped. In addition to that, where erosion and the marble quarries help to a good field observation the intense folded structure may lead to the false interpretation of stratigraphic repetition of marble and crystalline schists or metamorphosed intrusive. A similar strong folding of high elastic beds can be easily recognised in sites farther in east Attica i.e with horizontal folds of marbles in crystalline environment (Varkiza Barako hill, SE of Dionyssovouni etc).

On the contrary to the elastic, strongly folded central Attica (where the Athens Schists) and the entirely metamorphosed eastern Attica, in western Attica, from the eastern hillfoot of Aegaleo and Parnis westwards, folding is in general obtuse, of a long wavelength, with uncommon or lacking the extreme forms of vertical or horizontal folds, although stress pattern, as it is revealed by stratimetry and faulting, is generally the same applied in eastern Attica. That is, a NW to $\mathrm{W}$ strong compression, weaker towards NE, with a major tension result from NE to the E.According to the all above analysis, during the orogenic process the regional tectonic result seems to best conform to a kind of clash of the more plastic/less rigid structure of eastern Attica onto the more unyielding/elastic structure of western Attica, producing conditions for a mechanic/tectonic convenience, to benefit overriding westwards.

Folding is accompanied by shearing, with major elements the NW strike slip and NE reverse faults of restricted movement, as well as by a tension of the structure greater to the NE and to a less extent NWards.

Tension acted contemporarily to folding and later on to finish orogenic structure. To the latter process belong the NW and NE faults of the graben boundaries, that have been accommodated by prepared, mechanically weak routes of the preneogene structural process. As such faults are 


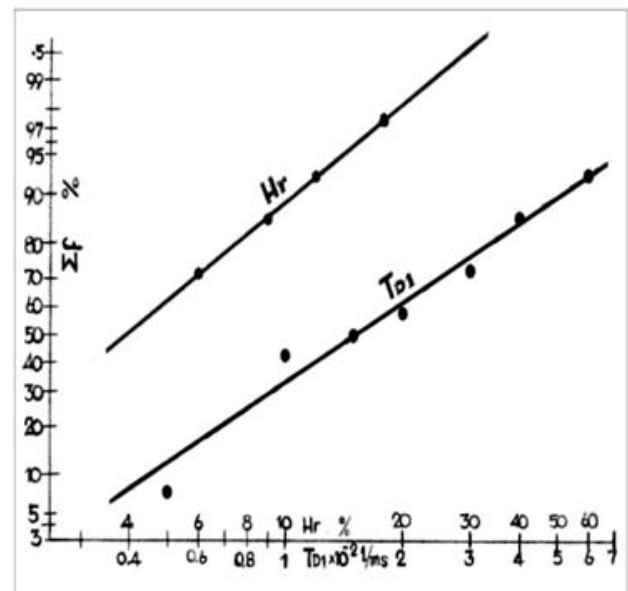

Fig. 2: Cumulative frequency $(\Sigma \mathrm{f})$ of the values of the hard rock component percentage (Hr) and of the transmissibility $\mathrm{T}$.

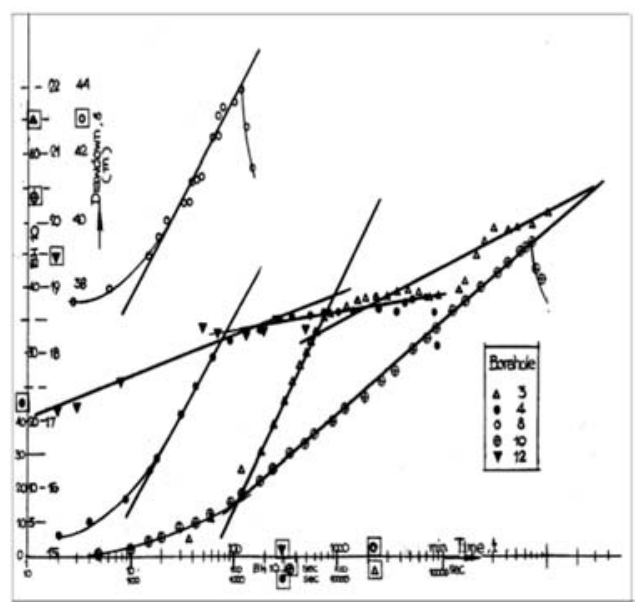

Fig. 3: Indicative diagrams of s vs. t.

understood indicatively, the major fault of the northern boundary of Thriassion Pedhion ( west of Athens) to the east through Zefyri - Kalogreza -Pallini, as well as the minor of Fili through Acharnae to Anthoussa, the NE striking of the boundaries of Aegaleo and Parnes (Fig.1) (Kounis, 1998).

\section{Hydrolithological structure and hydrological performance of the Schists of Athens}

\subsection{General}

The hydrogeological conditions in the Schists of Athens are quite significantly differentiated in the zones of thick limestone intercalations or effusives (Ilissos, Thission, Metaxourghion, Ag. Panteleimon - Kypseli), but also everywhere the percentage of calcareous, quartzite and sandstone contribution to the schists mass is increased, indifferently if in thin layers or disseminated. Differentiation is also recognized along the faulting zones where incoherence and brecciation are produced, commonly present and best performing hydrogeologically if tension originated. The fault case is particularly important for improving with depth hydraulic continuity.

Additionaly, where aquiferous quaternary overlies a weathering mantle of the schists, considerably thick, an improvement of the hydrogeological performance is observed. In this case is also calcareous and quartzitic component responsible for improved conditions.

Groundwater level morphology is compatible to the topographic surface and a noticeable flow takes place through the compined weathering mantle of the microfractured schists and the quaternary cover, if the latter is thick enough. Otherwise, and this is the case discussed, flow though weak, is undertaken by the "hard" zones of the Schists (Fig.1).

Beside the major collective zone along the Kifissos, in the Athens basin few minor but remarkable groundwater flow axes are formed and more specifically running through Ilissos, Leof. Alexandras, Iridanos, Lykabettus-Omonia, Erithros Stavros towards SW. Depth to ground- 
water level varies mostly in between $1 \mathrm{~m}$ and $20 \mathrm{~m}$, with the lower values measured in central Athens where Schists are shallow, the higher in the Kifissos flow convergence.

Schists of Athens are aquitards allowing weak flow, and the case refers to the upper hydraulically best performing layers. They become locally insufficient to provide water (aquicludes), particularly where shaly component and structure persist and prevail extensively, producing hydrogeological blockade of the "hard", fractured members and of their hydraulic continuity.

\subsection{The Transmissibility}

Transmissibility (T) of the Athens Schists is found low to very low, with the $96 \%$ of values calculated being less than $8.4 \times 10^{-2} 1 / \mathrm{sm}$ and the $50 \%$ of them less than $1.5 \times 10^{-2} 1 / \mathrm{sm}$. The range of values is $0.4 \mathrm{X} 10^{-2} 1 / \mathrm{sm}<\mathrm{T}<8.5 \mathrm{X} 10^{-2} 1 / \mathrm{sm}$ (Fig. 2), as it comes from pumping tests in boreholes under unsteady state conditions of flow. The Jacob approach is used and more specifically the first ,after the segment due to well storage, linear part of the diagram of drawdown (s) with time (t) from start of pumping on semilogarithmic paper (Fig.3) (Todd 1959; Kruseman et De Ridder, 1976).

Values from this first linear part inform about the performance of the borehole site and the immediate vicinity. Values of $\mathrm{T}$ from the next linear part of the diagram svs.logt have also been taken, where condition appeared. This segment mostly showed an additional delayed flow from rather leaky wheathering mantle of the Schists in the site neighbourhood, or flow from some improved fracturing of "hard" schist reached by depression cone, as its radius of influence expanded farther. A few svs.logt diagrams are indicatively given (Fig.3), while borehole sites are shown on the map (Fig. 1). Statistical distribution of values show a positive skewness and this conforms, as expected, to the permeability distribution (Krumbein and Graybill, 1965). As practically no accuracy is lost in the domain of values found, lognormal distribution is preferred and log-probability paper is used (Fig. 2).

\subsection{The competent to fracturing component}

Taking into account the lithological and structural conditions previously presented, it is the "hard" component of the Schists of Athens, layerd or disseminated, that shows a hydrogeological active fracturing in which groundwater is stored and flows.

Suffering tectonic stresses, especially in dynamic metamorphism conditions that hold extensively in the case studied, grain, brittle minerals are traversed by tension cracks strongly marked. (Harker 1962; Ramsay, 1967). In the case of selective, sorted deposition of these minerals in the form of layers of sandstone, limestone, quartzite or lenses and veinlets fracturing is particularly pronounced. In carbonate layers, internal erosion acted to the benefit of widening of fractures and of its performance. The more is spatially the abundance of the "hard" component of Schists with the associated fracturing, the better is hydrologically the athenian schists performance.

Entirely adverse effect has the "soft" component of schists of which ductile minerals and above all their depositional and metamorphic concentrations undergo significant shearing and folding, with the hydrologically active jointing playing practically a very second role in water flow. Fortunately, this disadvantage is to some extent counterbalanced by tensional detachments, which offer or improve hydraulic continuity in the mass. Jointing passes through the binary lithologic system and mostly diffracted at the boundaries. In the ductile, inelastic minerals and their depositional and metamorphic layers are understood the clay minerals (e.g caolin group) and those with primary micaceous, foliated and lamellar structure, or the dynamically similar. 


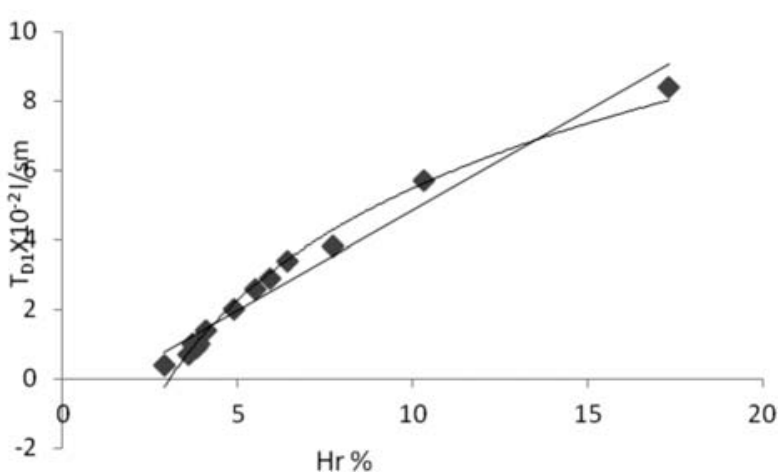

Fig. 4: Transmissibility $\left(\mathrm{T}_{\mathrm{D} 1}\right)$ vs. "Hard" rock component $(\mathrm{Hr})\left(\mathrm{T}_{\mathrm{D} 1}\right.$, from the first linear segment of drawdown vs. $\log$ time).

Measurements of the hard percentage over the whole sample have been taken from cuttings of boreholes (shown on the map). Diagnostically, on a given randomly taken sample, from a larger number of them from each borehole, white coloured greysh and hard cuttings represented calcitic, quartz and alike elements and were counted. Counted also were the friable cuttings, darkish coloured. A good magnification was accurately achieved. In certain samples microscopical observation and measurement was applied, as well.

Deviations among the samples in the specified borehole were efficiently distributed around a mean value kept for the further use. Where natural sections and particularly excavations for foundations existed, observations and measurements were taken. The counting was accomplished on a sufficient number of lines of adequate length each, and where possible perpendicular to the main structural feature (bedding etc). Results were well comparable to those of borehole cuttings and in most cases the latter were put in between.

When values were available from both approach methods, the mean value was finally accepted for correlation. Values (Hr) of "hard", competent to fracturing component of the Athens Schists show a positively skewed distribution, so that a log-propability fitting was preferred and shown on the diagram of Fig.2. Less than $50 \%$ of the values are in the range $\mathrm{Hr} \leq 0.04$, while $\mathrm{Hr}<0.36$ at a level of $99.75 \%$. In the distribution diagram included are also measurements from excavations distant of boreholes vicinity. Scattering of points from the various places is very good to fit this distribution.

\subsection{The relationship of transmissibility with the "hard"/competent to fracturing com- ponent.}

The hydrogeological qualification of the Schists of Athens is offered from the presence of the competent to fracturing rock phase in their composition, for the tectonic reasons and conditions previously presented. This qualification is reflected to the transmissibility $(\mathrm{T})$ values of the saturation zone. The regression of transmissibility values upon the percentage (Hr) of "hard" component shows a positive very good linear correlation. Using $T$ values from the first linear segment $\left(\mathrm{T}_{\mathrm{D} 1}\right)$ of the drawdown (s) with time (t) i.e svs. logt , according to the Jacob approach, we found out

$$
\mathrm{T}_{\mathrm{D} 1}=0.5779 \mathrm{Hr}-0.927 \text {, with a very high correlation coefficient, } \mathrm{r}=0.987 \text { (Fig.4) }
$$

The fitting of a logarithmic model made $\mathrm{r}$ higher and more specifically, we found that

$$
\mathrm{T}_{\mathrm{D} 1}=4.6191 \operatorname{lnHr}-5.1558 \text {, with } \mathrm{r}=0.9928(\text { Fig.4) }
$$


Table 1.

\begin{tabular}{|c|c|c|c|c|c|c|}
\hline $\begin{array}{l}\text { Ref. } \\
\text { No }\end{array}$ & $\begin{array}{c}T_{D I} x 10^{-2} \\
(l / s m)\end{array}$ & $\begin{array}{c}T_{D 2} x 10^{-2} \\
(l / s m)\end{array}$ & $\begin{array}{c}T_{(D I+D 2) / 2} x 10^{-2} \\
(\mathrm{l} / \mathrm{sm})\end{array}$ & $\begin{array}{l}H r \\
(\%)\end{array}$ & $\begin{array}{l}\text { BH Depth } \\
\text { (m) }\end{array}$ & Site \\
\hline 1 & 5.7 & & & 10.3 & 86 & Hilton \\
\hline 2 & 2.9 & & & 5.9 & 56 & Evangelismos \\
\hline 3 & 0.7 & 2.4 & 1.55 & 3.6 & 69 & Ag. Sostis \\
\hline 4 & 0.7 & 8 & 4.35 & 3.2 & 118 & Serafeion \\
\hline 5 & 0.9 & 3.6 & 2.25 & 3.8 & 85 & Filopappou \\
\hline 6 & 0.4 & 0.7 & 0.55 & 2.9 & 57 & Park Atlantos \\
\hline 7 & 1 & 0.5 & 0.75 & 3.7 & 56 & Akad Platonos \\
\hline 8 & 3.8 & & & 7.7 & 60 & Idryma Erevnon \\
\hline 9 & 1.38 & & & 4.1 & 58 & Lofos Koilis \\
\hline 10 & 2.6 & 6.6 & 4.6 & 5.5 & 92 & Plateia Antheon \\
\hline 11 & 3.4 & 10 & 6.7 & 6.4 & 108 & Evelpidon \\
\hline 12 & 8.4 & & & 17.3 & 74 & Plat. Irinis \\
\hline 13 & 2 & 15 & 8.5 & 4.9 & 73 & Plat. Argentinis \\
\hline 14 & 1 & 4 & 2.5 & 3.9 & 52 & Elenas \\
\hline
\end{tabular}

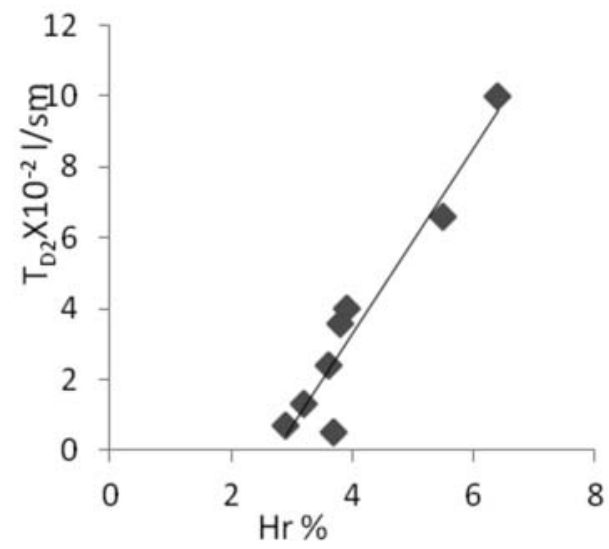

Fig. 5: Transmissibility $\left(\mathrm{T}_{\mathrm{D} 2}\right)$ vs. "Hard" rock component $(\mathrm{Hr})\left(\mathrm{T}_{\mathrm{D} 2}\right.$, from the second linear segment of drawdown vs. log time).

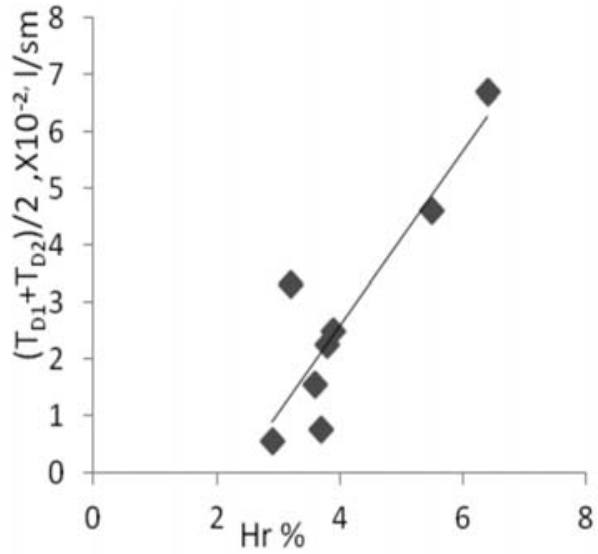

Fig. 6: Average Transmissibility (T) vs. "Hard" rock component $(\mathrm{Hr})\left(\mathrm{T}_{\mathrm{D} 1, \mathrm{D} 2}\right.$, as in Fig. 4,5).

To validate the idea of "hard" component being the vital factor for the hydrogeological performance use we made of transmissibility values from the second linear $\left(\mathrm{T}_{\mathrm{D} 2}\right)$ segment of the s vs logt approach.

The reasons this segment to appear is convincingly explained in a previous paragraph.

The relationship found is

$$
\mathrm{T}_{\mathrm{D} 2}=2.6131 \mathrm{Hr}-7.1416, \text { with } \mathrm{r}=0.9567(\text { Fig.5) }
$$


Taking mean values for the pairs $\mathrm{T}_{\mathrm{D} 1}$ and $\mathrm{T}_{\mathrm{D} 2}$, which is an approach not uncommon for the estimation of the transmissibility of aquifers with drawdown responding to time in this way, we found

$$
\mathrm{T}_{(\mathrm{D} 1+\mathrm{D} 2) / 2}=1.5334 \mathrm{Hr}-3.5464, \text { with } \mathrm{r}=0.8876 \text { (Fig. 6) }
$$

In Table 1 the sites of wells, transmissibility values, the percentage of "hard" component and other data are given.

\section{Conclusions}

Very low to low is the transmissibility of the schists of Athens with values usually not exceeding 300lit/hour.m.

With a hydraulic gradient of 0.02 to 0.05 , through a flow front that reasonably corresponds to an abstraction well the groundwater yield is about $2.2 \mathrm{~m}^{3} /$ hour.

The participation of the hard component and more specifically of the carbonates, sandstones, quartzites and the alike in the form of layers, lenses, veinlets usually does not exceed $30 \%$ of the whole composition.

A linear correlation of transmissibility $(\mathrm{T})$ with "hard" rock percentage $(\mathrm{Hr})$ seems to hold for the Schists of Athens, at least in the domains of values $0.2 \times 10^{-2} 1 / \mathrm{sm}<\mathrm{T}<8.5 \times 10^{-2} 1 / \mathrm{sm}$ and $3 \%$ $<\mathrm{Hr}<18 \%$.

We think worthwhile, the relationship of T vs. Hr whatever it will be, to be searched in similar to schists of Athens formations.

An approximate prediction/estimation of the groundwater yield of a similar formation could be made on the basis of measurements of "hard" component percentage in natural or artificial field sections.

\section{References}

Dounas, A., Kallergis, G., Morphis, A. 1976. Hydrogeological investigation within the framework of the study for the Athens metropolitan underground railway(METRO). Hydrological and Hydrogeological Investigation, 19 IGME, Athens.

Dounas, A., Kallergis, G., Morphis, A. 1980. Contribution on the knowledge of the tectonic relation between the Parnes system and the metamorphic sequence of Grammaticon.Publications Office of the Academy of Athens vol. 54 (in greek).

Harker, A. 1962. Petrology for students. Cambridge University Press.

Gaitanakis, P., 1982. Geological map of Greece. Athinae- Piraieus sheet. 1 to 50000. IGME, Athens.

Katsikatsos, G., Kounis, G., Antoniades, P., Mettos, A., Papadopoulos, P., Gakis, A., 1976. Geological map of Metro area, 1 to 7500. IGME, Athens.

Katsikatsos, G., Mettos, A., Vidakis, M., Dounas, A., 1986 Geological map of Greece. Athinae Elefsis sheet, 1 to 50000. IGME, Athens.

Katsikatsos, G. 2002. Geological map of Greece. Kifissia sheet 1 to 50000. IGME, Athens.

Koumantakis, J. 1998. Subsidences due to overpumping of ground waters. Necessary interventions. Nat. Tech. University of Athens.

Kounis, G. D. 1980 On the hydrogeological conditions of the area of the solar village no.3, 
Lykovrissi Attica. Hydrological and Hydrogeological Investigations, 33. IGME, Athens.

Kounis, G. D. 1980. Athens Metro hydrogeological research. I Measurements and II Analysis of the hydrogeological Conditions. Hydrological and Hydrogeological Investigations, 34. IGME, Athens.

Kounis, G.D 1998.A study for the hydrogeology of Attica.. IGME, Athens.

Krumbein, W.C,Graybill, F.A,1965.An Introduction to statistical models in geology Mc Graw-Hill Book Co.

Kruseman,G.P. and De Ridder N.A.1976.Analysis and evaluation of pumping test data. International Institute for land reclamation and improvement.1976.Wageningen,The Netherlands.

Marinos, P.G. 1991.Chapters of Engineering Geology. Nat. Tech. University of Athens.

Ramsay, J.G 1967. Folding and fracturing of rocks. Mc Graw-Hill Book Co.

Todd, D.K. 1959. Groundwater hydrology. John Wiley and Sons, NewYork. 